\title{
Article \\ A Non-Volatile Tunable Terahertz Metamaterial Absorber Using Graphene Floating Gate
}

\author{
Jinjun Bai ${ }^{1, *}$, Wei Shen ${ }^{1}$, Jia Shi ${ }^{1}\left(\mathbb{D}\right.$, Wei Xu ${ }^{1}{ }^{\oplus}$, Shusheng Zhang ${ }^{1}$ and Shengjiang Chang ${ }^{2}$ \\ 1 Tianjin Key Laboratory of Optoelectronic Detection Technology and Systems, \\ School of Electrical and Electronic Engineering, Tiangong University, Tianjin 300387, China \\ wsshenwei@126.com (W.S.); shijia@tiangong.edu.cn (J.S.); xuwei@tiangong.edu.cn (W.X.); \\ damutou2016@163.com (S.Z.) \\ 2 Institute of Modern Optics, Nankai University, Tianjin 300071, China; sjchang@nankai.edu.cn \\ * Correspondence: baijinjun@tiangong.edu.cn; Tel.: +86-022-83955164
}

check for updates

Citation: Bai, J.; Shen, W.; Shi, J.; Xu, W.; Zhang, S.; Chang, S. A

Non-Volatile Tunable Terahertz

Metamaterial Absorber Using

Graphene Floating Gate.

Micromachines 2021, 12, 333.

https://doi.org/10.3390/mi12030333

Academic Editor: Bassem Salem

Received: 7 March 2021

Accepted: 18 March 2021

Published: 21 March 2021

Publisher's Note: MDPI stays neutral with regard to jurisdictional claims in published maps and institutional affiliations.

Copyright: (C) 2021 by the authors. Licensee MDPI, Basel, Switzerland. This article is an open access article distributed under the terms and conditions of the Creative Commons Attribution (CC BY) license (https:// creativecommons.org/licenses/by/ $4.0 /)$.

\begin{abstract}
Based on the graphene floating gate, a tunable terahertz metamaterial absorber is proposed. Compared with the traditional graphene-dielectric-metal absorber, our absorber has the property of being non-volatile and capacity for anti-interference. Using the finite element method, the paper investigates the absorption spectra, the electric field energy distribution, the tunability and the physical mechanism. In addition, we also analyse the influence of geometry, polarization and incident angles on the absorption. Simulation results show that the bandwidth of the absorption above $90 \%$ can reach up to $2.597 \mathrm{THz}$ at the center frequency of $3.970 \mathrm{THz}$, and the maximum absorption can be tuned continuously from $14.405 \%$ to $99.864 \%$ by controlling the Fermi level from $0 \mathrm{eV}$ to $0.8 \mathrm{eV}$. Meanwhile, the proposed absorber has the advantages of polarization insensitivity and a wide angle, and has potential applications in imaging, sensing and photoelectric detection.
\end{abstract}

Keywords: floating gate; graphene; non-volatile; terahertz; tunable

\section{Introduction}

Terahertz $(\mathrm{THz})$ waves have proven to be promising applications in the areas of imaging [1], communication [2,3] and biomedical science [4,5], due to their superior properties. However, the lag of $\mathrm{THz}$ devices has become one of the main obstacles to their application in practice, because of the lack of ideal functional materials. The emergence of metamaterial provides a way for the design and fabrication of $\mathrm{THz}$ devices. In particular, since it was reported in 2008 [6], the THz metamaterial absorber (MMA) has been attracting a lot of interest. The single-band [7-9], multi-band [10-12] and broadband [13-15] absorbers have been widely investigated. However, these absorbers cannot meet the tunable requirement in complicated electromagnetic circumstances.

Graphene possesses many unique electronic and optical properties, which can be applied in solar cells [16] and other photonic applications. The optical conductivity of graphene can be changed by electrostatic or chemical doping, so it can be used in tunable MMAs. Currently, several methods are available to design tunable absorbers, such as temperature [17-19], voltage [20-25], light [26,27] and mechanics [28]. Among them, the voltage tunable $\mathrm{THz}$ graphene MMA is dominant because it is convenient and flexible. There are two kinds of graphene tunable MMAs: frequency modulators [29-34] and amplitude modulators [35-37]. The former mainly include single-band and multi-band absorbers. The latter mainly include broadband absorbers. However, these absorbers are susceptible to interference, because their absorption behaviors are closely related with the external bias voltage.

To improve the anti-interference ability of the absorbers, we designed a non-volatile tunable $\mathrm{THz}$ MMA by using the graphene floating gate. In the off condition of external bias voltage, the absorption of the absorber can still maintain stability. Compared with the 
traditional tunable terahertz absorber, our absorber has the property of being non-volatile and capacity for anti-interference. Furthermore, the results indicate that the frequency range of absorption above $90 \%$ is $2.671 \mathrm{THz}$ to $5.268 \mathrm{THz}$, and the tuning depth of maximum absorption is $85.575 \%$. Meanwhile, the proposed absorber has the advantages of polarization insensitivity and a wide angle.

\section{Structure and Design}

Figure 1a shows the periodic unit schematic of the proposed THz MMA, which has a square cross section. From bottom to top, the structure is composed of a substrate layer (gold), dielectric layer (silicon dioxide), lower conductive layer (p-type doped silicon), gate layer (silicon dioxide), graphene composite layer (graphene-SiO ${ }_{2}$ ), isolation layer (aluminum oxide) and upper conductive layer (p-type Si), where the graphene composite layer is made up of silicon dioxide embedded in a graphene block. The conductivity of gold is $\sigma=4.09 \times 10^{7} \mathrm{~S} / \mathrm{m}$ [38]. The dispersion properties are ignored. The permittivities of $\mathrm{SiO}_{2}$ and $\mathrm{Al}_{2} \mathrm{O}_{3}$ are $\varepsilon=3.80$ [18] and $\varepsilon=9.39$ [39], respectively. The dielectric property of the p-type doped silicon is shown in Figure 2. The transmission coefficient is equal to zero for the existence of a gold substrate. Therefore, the formula of absorption can be simplified as [40]: $A(\omega)=1-R(\omega)=1-\left|S_{11}\right|^{2}$, where $R(\omega)$ is reflectivity, $\mathrm{S}_{11}$ is reflection coefficient.

The graphene floating gate consists of the top five layers of the absorber, as shown in Figure 1b. It works like this [41]: with forward bias voltage (the upper conductive layer takes the positive power supply, the lower conductive layer is connected with the negative), the electrons in the lower conductive layer can tunnel through the gate layer into the graphene composite layer to increase its carrier concentration. Conversely, when a reverse bias voltage is applied, the electrons in graphene can tunnel through the gate layer, leading to a decrease in its carrier concentration. Note that the electrons cannot tunnel through the isolation layer because its thickness is twice that of the gate layer. When the bias voltage is disconnected, the graphene is isolated from the external environment so that its carrier concentration and the absorption of the absorber can remain unchanged. The non-volatile property of floating gates enhances the ability of the absorber of resistance to disturbance.

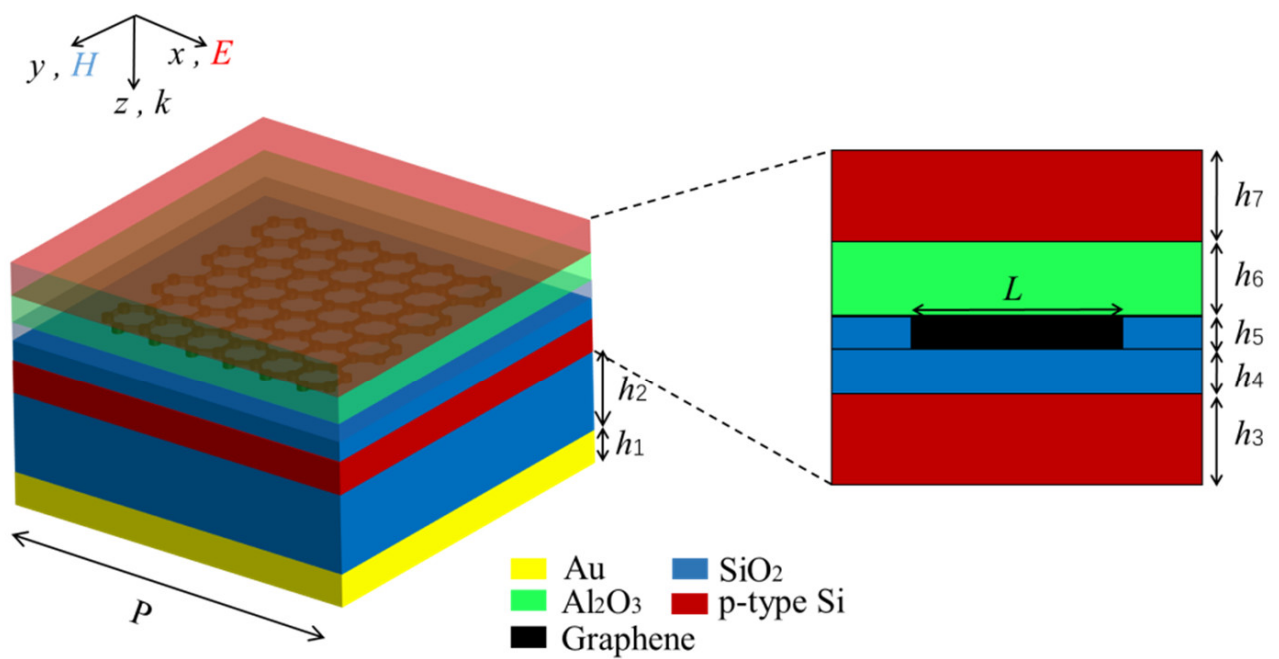

(a)

(b)

Figure 1. 3D schematic (a) and side view of floating gate $(\mathbf{b})$. The geometrical dimensions are $P=13$ $\mu \mathrm{m}, L=7.2 \mu \mathrm{m}, h_{1}=0.2 \mu \mathrm{m}, h_{2}=8.4 \mu \mathrm{m}, h_{3}=0.2 \mu \mathrm{m}, h_{4}=10 \mathrm{~nm}, h_{5}=1 \mathrm{~nm}, h_{6}=20 \mathrm{~nm}, h_{7}=0.2 \mu \mathrm{m}$. The values of $h_{4}$ and $h_{6}$ are derived from reference [41]. 


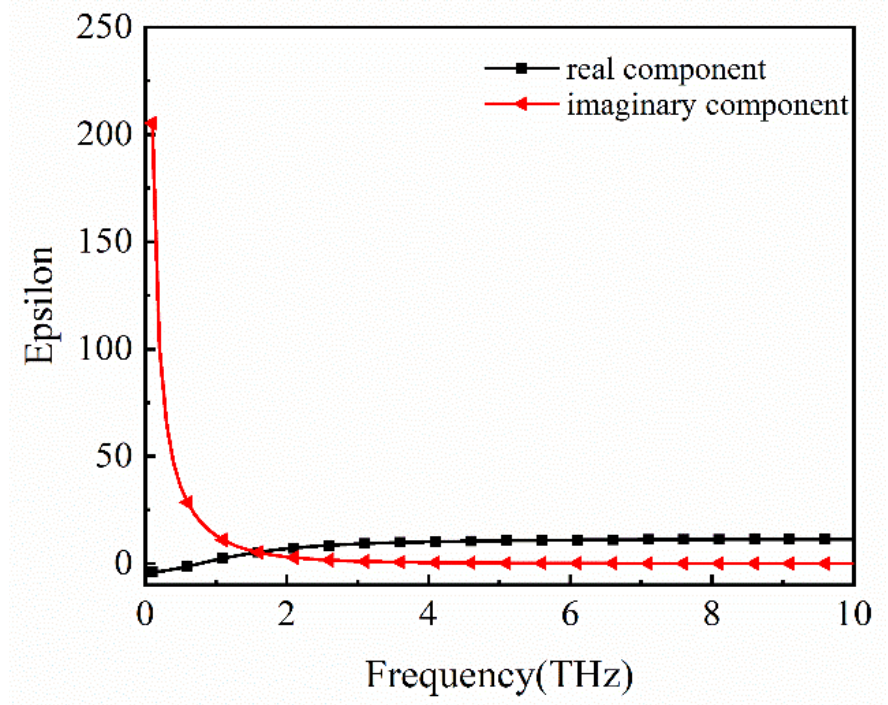

Figure 2. Dielectric property of the p-type doped silicon in $\mathrm{THz}$ band. It is described by the Drude model [14] as $\varepsilon=\varepsilon_{\infty}-\frac{\omega_{p}^{2}}{\omega^{2}+i \gamma \omega}$, where $\varepsilon_{\infty}=11.7$ is the constant permittivity at the infinite frequency, plasma frequency $\omega_{p}$ and collision frequency $\gamma$ are set to $2 \pi \times 5.22 \mathrm{THz}$ and $2 \pi \times 1.32 \mathrm{THz}$, the corresponding carrier concentration and electron mobility are $8.8 \times 10^{16} \mathrm{~cm}^{-3}$ and $814.3 \mathrm{~cm}^{2} \mathrm{~V}^{-1} \mathrm{~s}^{-1}$, respectively.

\section{Results and Discussion}

\subsection{Simulation Results and Mechanism Analysis}

The absorption spectrum is presented in Figure 3. The full-wave simulation was performed by CST Microwave Studio based on the finite element method (FEM). Adaptive tetrahedral mesh refinement has been used. In the simulation, the Fermi level of graphene is $0.8 \mathrm{eV}$, and the scattering time is assumed as $0.1 \mathrm{ps}$ [42]. As can be seen from the figure, the bandwidth with absorption above $90 \%$ is $2.597 \mathrm{THz}$ at the center frequency of $3.970 \mathrm{THz}$. There exist two absorption peaks, corresponding to absorption of $99.859 \%$ at $2.995 \mathrm{THz}$ and $96.926 \%$ at $4.808 \mathrm{THz}$.

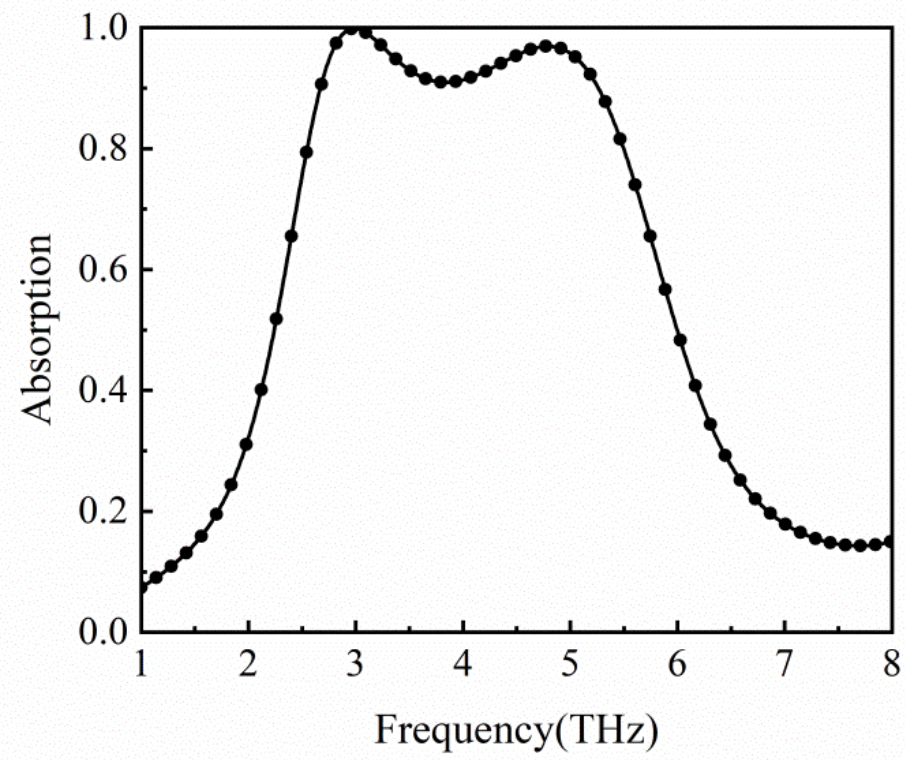

Figure 3. Absorption spectrum of the absorber for Fermi level $E_{f}=0.8 \mathrm{eV}$. The bandwidth with absorption above $90 \%$ is $2.597 \mathrm{THz}$. There exist two absorption peaks, $2.995 \mathrm{THz}$ and $4.808 \mathrm{THz}$.

To grasp the physical mechanism of the absorber, the electric field distributions of the graphene composite layer at $2.995 \mathrm{THz}$ and $4.808 \mathrm{THz}$ are calculated, as shown in Figure 4 . 
It is evident from Figure 4a that the electric field energy is mainly concentrated on the left and right edges of the graphene. The resonance direction of the dipole is horizontal, which is the transverse surface plasmon resonance mode. Similarly, in Figure $4 \mathrm{~b}$, the absorption peak at $4.808 \mathrm{THz}$ results from the longitudinal plasmon mode. Thus, the strong absorption is attributed to the plasmon resonance, which results in the electric field energy being localized at the edge of the graphene. The reason for the wide bandwidth is the superposition of the longitudinal and transverse surface plasmon resonance modes [37].

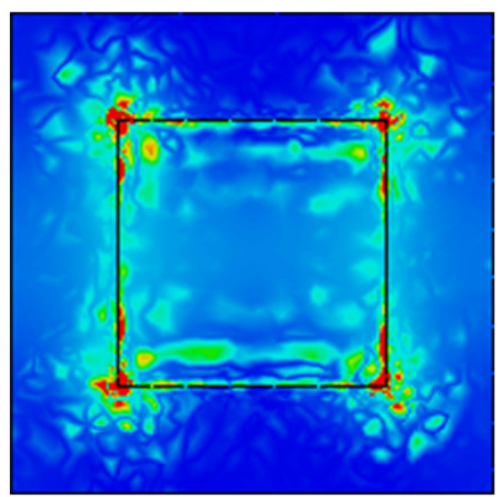

(a)

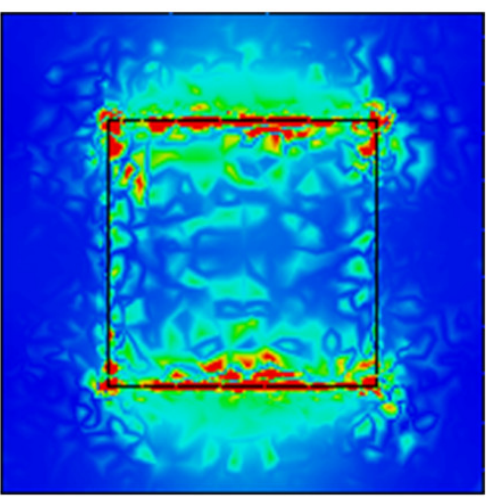

(b)

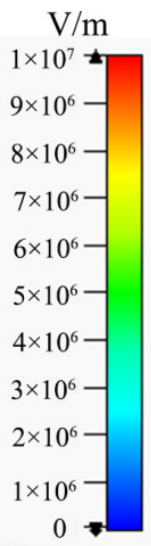

Figure 4. Electric field distributions of the graphene composite layer at resonance frequencies of (a) $2.995 \mathrm{THz}$ and (b) $4.808 \mathrm{THz}$.

According to the above analysis, the absorbing performance of the absorber is closely related to the graphene composite layer. So, we compute the influence of the graphene geometries on the absorption spectra, as shown in Figure 5. With the increase in the side length $L$, the bandwidth of the absorber broadens monotonously and the maximum absorptivity increases gradually. That is because the bigger the side length $L$ is, the farther the spacing between two resonance frequencies of the transverse and longitudinal plasmon resonances is. Meanwhile, the ability to localize the electric field becomes stronger as the side length $L$ increases.

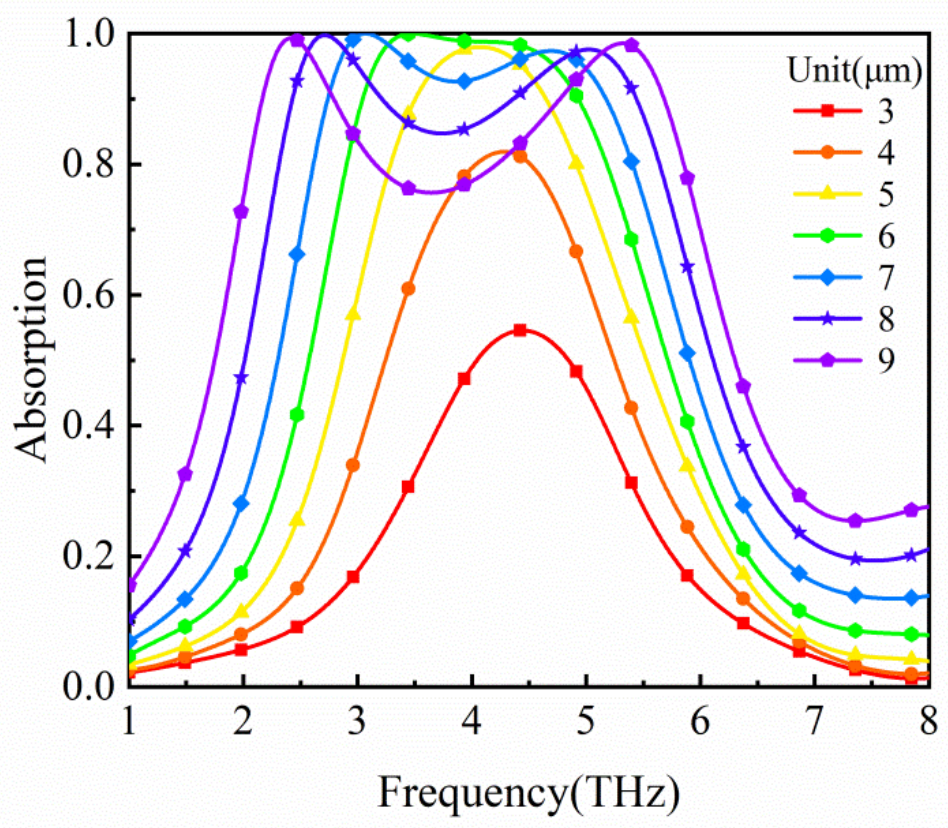

Figure 5. Absorption spectra of the absorber for different graphene side lengths. 
In a perfect absorber design, the impedance matching plays an important role, which mainly depends on the thickness $\mathrm{h}_{2}$ of the dielectric layer for the proposed absorber. So, we calculated the influence of the thickness on the absorption spectra, as shown in Figure 6. It shows that with the increase in $\mathrm{h}_{2}$, the absorption firstly increases and then decreases, due to the realization of a good impedance match between the absorber and the free space near $h_{2}=9 \mu \mathrm{m}$. When $h_{2}$ deviates from $9 \mu \mathrm{m}$, the impedance mismatch results in a decrease in absorption.

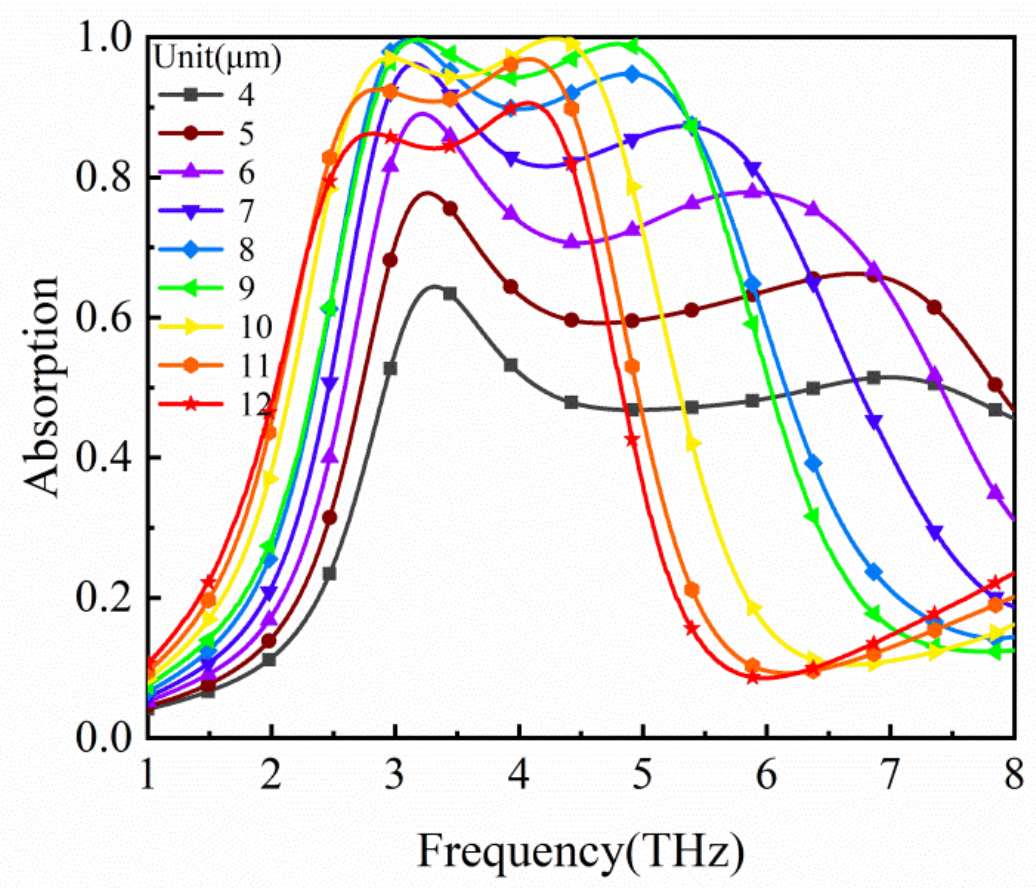

Figure 6. Absorption spectra of the absorber for different dielectric layer thicknesses.

\subsection{Frequency Tunability and Insensitivity}

The tunability of the absorber is realized by graphene, because the Fermi level of the graphene can be adjusted by changing the applied voltage. Graphene in a floating gate can capture the tunneled electrons under the positive applied voltage, which increases the charge density. On the contrary, graphene, under the reverse applied voltage, can release electrons, leading to a decrease in its charge density. The relationship between Fermi level $E_{f}$ and charge density $n_{g}$ of graphene is as follows [34,43]: $E_{f} \approx \mu_{g}=\operatorname{sgn}\left(n_{g}\right) \hbar v_{F} \sqrt{\left(\pi\left|n_{g}\right|\right)}$, where $v_{F}=0.9 \times 10^{6} \mathrm{~m} \cdot \mathrm{s}^{-1}$ is the Fermi velocity. The change of charge density is the reason why graphene has tunability. To confirm the tunable capacity of the absorber, we calculated its absorption spectra for different $E_{f}$ in Figure 7 . What can be clearly seen in this figure is the continual growth of the maximum absorption from $14.405 \%$ to $99.864 \%$ when varying the $E_{f}$ from 0 to $0.8 \mathrm{eV}$. When the Fermi level increases to $0.5 \mathrm{eV}$, the absorptivity is over $80 \%$. Furthermore, the electric field distributions of the graphene composite layer at the center frequency of $3.970 \mathrm{THz}$ for different Fermi levels are shown in Figure 8. It can be found that the resonance is enhanced due to the increase in surface plasmon at the upper and lower edges in Figure 8a-h. When $E_{f} \geq 0.5 \mathrm{eV}$, the increase in the absorption slows down and the electric field has a slight change. Moreover, as the $E_{f}$ changes from $0 \mathrm{eV}$ to $0.7 \mathrm{eV}$, the electric field energy is continuously concentrated. The reason is that the higher the $E_{f}$, the lower the intrinsic loss of graphene [29]. It is helpful for the enhancement of surface plasmon resonance and the improvement of absorbing ability. 


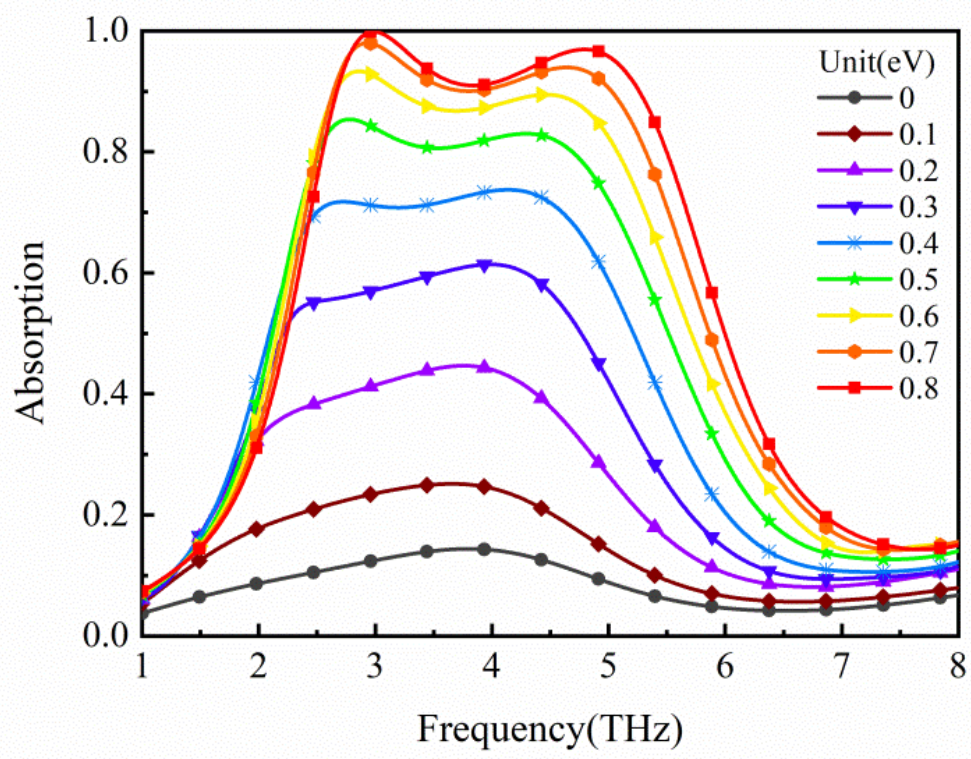

Figure 7. Absorption spectra of the proposed absorber with different Fermi levels $E_{f}$ of graphene (0-0.8 eV).

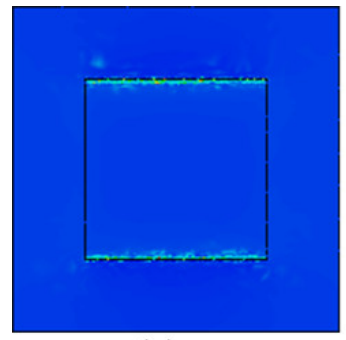

(a)

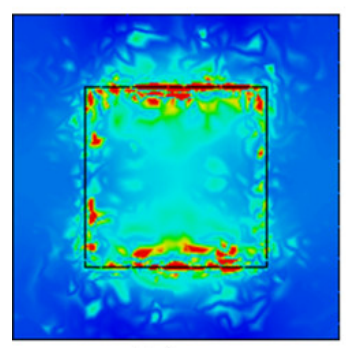

(e)

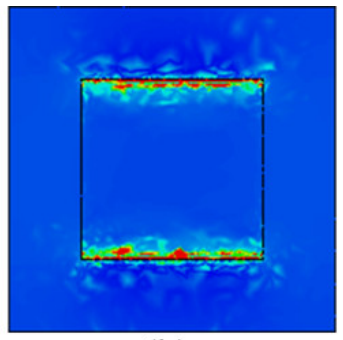

(b)

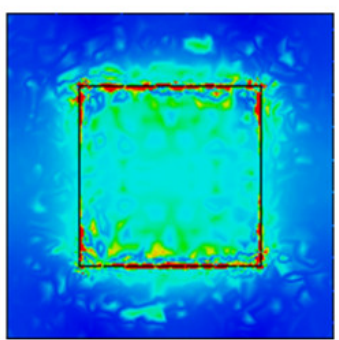

(f)

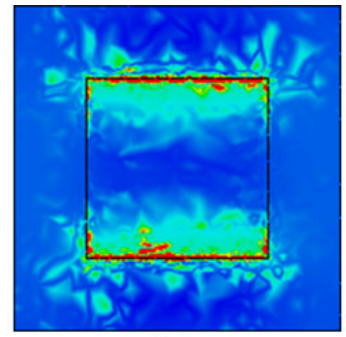

(c)

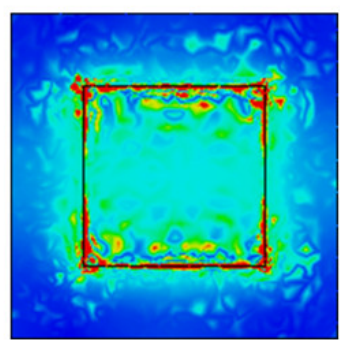

(g)

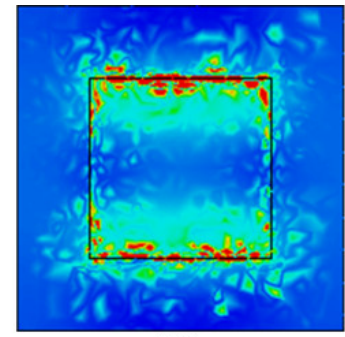

(d)

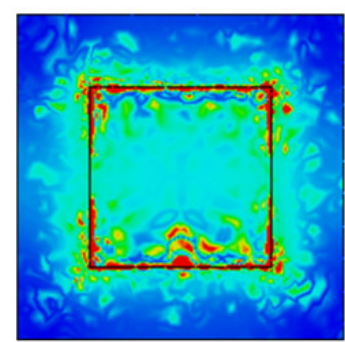

(h)

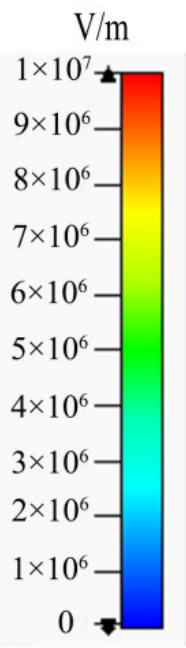

Figure 8. Electric field distributions of the graphene composite layer at the center frequency of $3.970 \mathrm{THz}$ for different Fermi levels of $0-0.7 \mathrm{eV}(\mathbf{a}-\mathbf{h})$.

In addition, we also investigate the sensitivity to polarization and the robustness of oblique incidence for the proposed absorber, and its corresponding absorption spectra are shown in Figures 9 and 10. As can be seen from Figure 9, the absorber is polarization insensitive owing to the rotational symmetry of the periodic unit. One can find from Figure 10 that broadband strong absorption (absorption $>80 \%$ ) can still be achieved for transverse electric (TE) and transverse magnetic (TM) polarization, when the incident angle is less than $45^{\circ}$. 


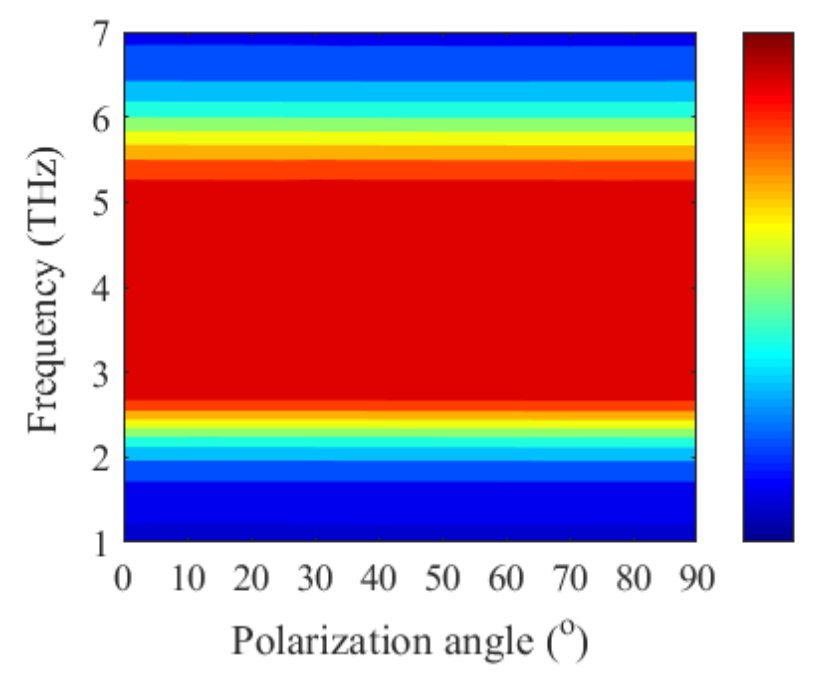

Figure 9. Absorption spectra of the absorber at various polarization angles.
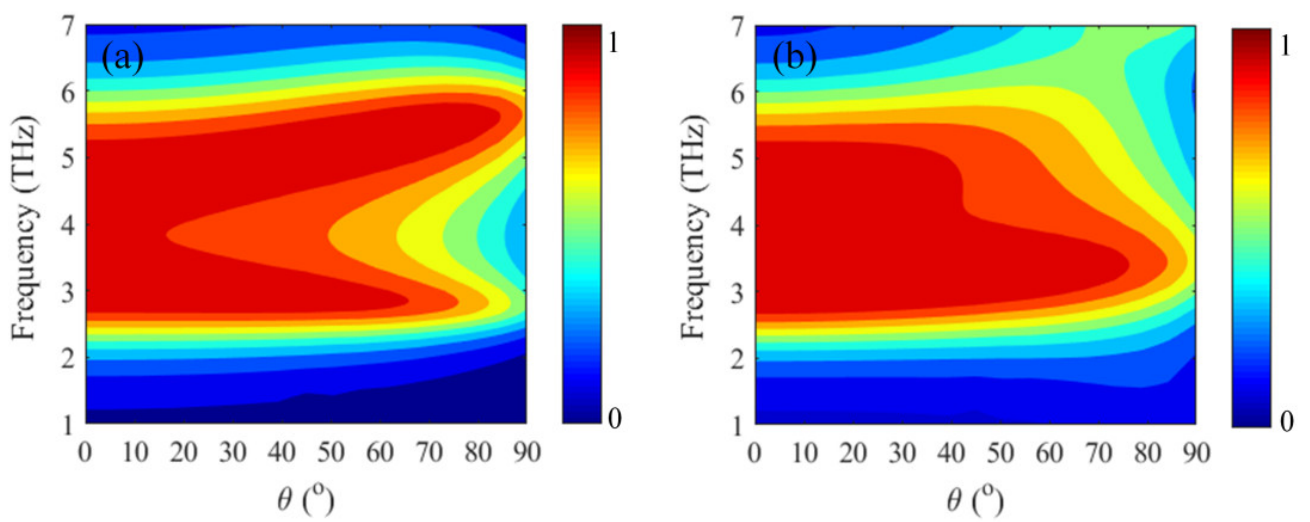

Figure 10. Absorption spectra with various incident angles for (a) transverse electric (TE) polarization and (b) transverse magnetic (TM) polarization.

\section{Conclusions}

In this paper, we propose a broadband, tunable, non-volatile, polarization-insensitive and wide-angle THz MMA based on a graphene floating gate. The absorption of the absorber can be dynamically tuned by changing the Fermi level of graphene and the depth of the tuning reaches up to $85.575 \%$. More importantly, it can maintain a stable absorption performance even if the external bias voltage is disconnected. The proposed absorber shows potential applications in terahertz detecting, imaging, sensing and stealth areas.

Author Contributions: All authors contributed to the study conception and design. Material preparation, data collection and analysis were performed by J.B., W.S., J.S., W.X., S.Z. and S.C. The first draft of the manuscript was written by W.S. and all authors commented on previous versions of the manuscript. All authors have read and agreed to the published version of the manuscript.

Funding: This work was supported by the Education Commission Research Project of Tianjin (Grant No. 2018KJ213).

Conflicts of Interest: The authors declare no conflict of interest.

\section{References}

1. Theofanopoulos, P.C.; Sakr, M.; Trichopoulos, G.C. Multistatic Terahertz Imaging Using the Radon Transform. IEEE Trans. Antennas Propag. 2019, 67, 2700-2709. [CrossRef]

2. Nagatsuma, T.; Ducournau, G.; Renaud, C.C. Advances in terahertz communications accelerated by photonics. Nat. Photonics 2016, 10, 371-379. [CrossRef] 
3. Jia, S.; Pang, X.D.; Ozolins, O.; Yu, X.B.; Hu, H.; Yu, J.L.; Guan, P.Y.; Da Ros, F.; Popov, S.; Jacobsen, G.; et al. 0.4 THz Photonic-Wireless Link With 106 Gb/s Single Channel Bitrate. J. Lightwave Technol. 2018, 36, 610-616. [CrossRef]

4. Yang, X.; Zhao, X.; Yang, K.; Liu, Y.P.; Liu, Y.; Fu, W.L.; Luo, Y. Biomedical Applications of Terahertz Spectroscopy and Imaging. Trends Biotechnol. 2016, 34, 810-824. [CrossRef]

5. Shi, J.; Wang, Y.Y.; Chen, T.N.; Xu, D.G.; Zhao, H.L.; Chen, L.Y.; Yan, C.; Tang, L.H.; He, Y.X.; Feng, H.; et al. Automatic evaluation of traumatic brain injury based on terahertz imaging with machine learning. Opt. Express 2018, 26, 6371-6381. [CrossRef]

6. Tao, H.; Landy, N.I.; Bingham, C.M.; Zhang, X.; Averitt, R.D.; Padilla, W.J. A metamaterial absorber for the terahertz regime: Design, fabrication and characterization. Opt. Express 2008, 16, 7181-7188. [CrossRef] [PubMed]

7. Alves, F.; Kearney, B.; Grbovic, D.; Lavrik, N.V.; Karunasiri, G. Strong terahertz absorption using $\mathrm{SiO}_{2} / \mathrm{Al}_{\text {based metamaterial }}$ structures. Appl. Phys. Lett. 2012, 100, 111104. [CrossRef]

8. Li, J.S. High absorption terahertz-wave absorber consisting of dual-C metamaterial structure. Microw. Opt. Technol. Lett. 2013, 55, 1185-1189. [CrossRef]

9. Wen, Q.Y.; Zhang, H.W.; Xie, Y.S.; Yang, Q.H.; Liu, Y.L. Dual band terahertz metamaterial absorber: Design, fabrication, and characterization. Appl. Phys. Lett. 2009, 95, 241111. [CrossRef]

10. Wang, B.X.; Zhai, X.; Wang, G.Z.; Huang, W.Q.; Wang, L.L. Design of a Four-Band and Polarization-Insensitive Terahertz Metamaterial Absorber. IEEE Photonics J. 2015, 7, 1-8. [CrossRef]

11. Shen, X.P.; Yang, Y.; Zang, Y.Z.; Gu, J.Q.; Han, J.G.; Zhang, W.L.; Cui, T.J. Triple-band terahertz metamaterial absorber: Design, experiment, and physical interpretation. Appl. Phys. Lett. 2012, 101, 151402. [CrossRef]

12. Mao, Z.W.; Liu, S.B.; Bian, B.R.; Wang, B.Y.; Ma, B.; Chen, L.; Xu, J.Y. Multi-band polarization-insensitive metamaterial absorber based on Chinese ancient coin-shaped structures. J. Appl. Phys. 2014, 115, 1-8. [CrossRef]

13. Zhu, J.F.; Ma, Z.F.; Sun, W.J.; Ding, F.; He, Q.; Zhou, L.; Ma, Y.G. Ultra-broadband terahertz metamaterial absorber. Appl. Phys. Lett. 2014, 105, 021102. [CrossRef]

14. Zhao, Y.T.; Wu, B.A.; Huang, B.J.; Cheng, Q.A. Switchable broadband terahertz absorber/reflector enabled by hybrid graphenegold metasurface. Opt. Express 2017, 25, 7161-7169. [CrossRef] [PubMed]

15. Huang, L.; Chowdhury, D.R.; Ramani, S.; Reiten, M.T.; Luo, S.N.; Taylor, A.J.; Chen, H.T. Experimental demonstration of terahertz metamaterial absorbers with a broad and flat high absorption band. Opt. Lett. 2012, 37, 154-156. [CrossRef]

16. Ghadiri, M.; Kang, A.K.; Gorji, N.E. XRD characterization of graphene-contacted perovskite solar cells: Moisture degradation and dark-resting recovery. Superlattices Microstruct. 2020, 146, 106677. [CrossRef]

17. Bai, J.J.; Zhang, S.S.; Fan, F.; Wang, S.S.; Sun, X.D.; Miao, Y.P.; Chang, S.J. Tunable broadband THz absorber using vanadium dioxide metamaterials. Opt. Commun. 2019, 452, 292-295. [CrossRef]

18. Song, Z.Y.; Wang, K.; Li, J.W.; Liu, Q.H. Broadband tunable terahertz absorber based on vanadium dioxide metamaterials. Opt. Express 2018, 26, 7148-7154. [CrossRef]

19. Zhu, J.; Han, J.; Tian, Z.; Gu, J.; Chen, Z.; Zhang, W. Thermal broadband tunable Terahertz metamaterials. Opt. Commun. 2011, 284, 3129-3133. [CrossRef]

20. Luo, C.Y.; Li, D.; Yao, J.Q.; Ling, F.R. Direct thermal tuning of the terahertz plasmonic response of semiconductor metasurface. J. Electromagn. Waves Appl. 2015, 29, 2512-2522. [CrossRef]

21. Yuan, H.; Zhu, B.O.; Feng, Y. A frequency and bandwidth tunable metamaterial absorber in x-band. J. Appl. Phys. 2015, 117, 173103. [CrossRef]

22. Zhao, J.; Cheng, Q.; Chen, J.; Qi, M.Q.; Jiang, W.X.; Cui, T.J. A tunable metamaterial absorber using varactor diodes. New J. Phys. 2013, 15, 043049. [CrossRef]

23. Peng, J.; He, X.; Shi, C.; Leng, J.; Lin, F.; Liu, F.; Zhang, H.; Shi, W. Investigation of graphene supported terahertz elliptical metamaterials. Phys. E-Low-Dimens. Syst. Nanostruct. 2020, 124, 114309. [CrossRef]

24. He, X.Y.; Lin, F.T.; Liu, F.; Shi, W.Z. Tunable strontium titanate terahertz all-dielectric metamaterials. J.Phys. D-Appl. Phys. 2020, 53, 155105. [CrossRef]

25. He, X.; Lin, F.; Liu, F.; Zhang, H. Investigation of Phonon Scattering on the Tunable Mechanisms of Terahertz Graphene Metamaterials. Nanomaterials 2020, 10, 39. [CrossRef] [PubMed]

26. Cheng, Y.Z.; Gong, R.Z.; Cheng, Z.Z. A photoexcited broadband switchable metamaterial absorber with polarization-insensitive and wide-angle absorption for terahertz waves. Opt. Commun. 2016, 361, 41-46. [CrossRef]

27. Shen, X.P.; Cui, T.J. Photoexcited broadband redshift switch and strength modulation of terahertz metamaterial absorber. J. Opt. 2012, 14, 114012. [CrossRef]

28. Hu, F.R.; Qian, Y.X.; Li, Z.; Niu, J.H.; Nie, K.; Xiong, X.M.; Zhang, W.T.; Peng, Z.Y. Design of a tunable terahertz narrowband metamaterial absorber based on an electrostatically actuated MEMS cantilever and split ring resonator array. J. Opt. 2013, 15, 055101. [CrossRef]

29. Chen, M.; Sun, W.; Cai, J.; Chang, L.; Xiao, X. Frequency-tunable terahertz absorbers based on graphene metasurface. Opt. Commun. 2017, 382, 144-150. [CrossRef]

30. Wang, L.; Ge, S.; Hu, W.; Nakajima, M.; Lu, Y. Graphene-assisted high-efficiency liquid crystal tunable terahertz metamaterial absorber. Opt. Express 2017, 25, 23873-23879. [CrossRef]

31. Wang, Y.; Song, M.; Pu, M.; Gu, Y.; Hu, C.; Zhao, Z.; Wang, C.; Yu, H.; Luo, X. Staked Graphene for Tunable Terahertz Absorber with Customized Bandwidth. Plasmonics 2016, 11, 1201-1206. [CrossRef] 
32. Yao, G.; Ling, F.; Yue, J.; Luo, C.; Ji, J.; Yao, J. Dual-band tunable perfect metamaterial absorber in the THz range. Opt. Express 2016, 24, 1518-1527. [CrossRef]

33. Zhang, Q.; Ma, Q.; Yan, S.; Wu, F.; He, X.; Jiang, J. Tunable terahertz absorption in graphene-based metamaterial. Opt. Commun. 2015, 353, 70-75. [CrossRef]

34. Zhang, Y.; Feng, Y.; Zhu, B.; Zhao, J.; Jiang, T. Graphene based tunable metamaterial absorber and polarization modulation in terahertz frequency. Opt. Express 2014, 22, 22743-22752. [CrossRef] [PubMed]

35. Andryieuski, A.; Lavrinenko, A.V. Graphene metamaterials based tunable terahertz absorber: Effective surface conductivity approach. Opt. Express 2013, 21, 9144-9155. [CrossRef]

36. Torabi, E.S.; Fallahi, A.; Yahaghi, A. Evolutionary Optimization of Graphene-Metal Metasurfaces for Tunable Broadband Terahertz Absorption. IEEE Trans. Antennas Propag. 2017, 65, 1464-1467. [CrossRef]

37. Xiao, B.; Gu, M.; Xiao, S. Broadband, wide-angle and tunable terahertz absorber based on cross-shaped graphene arrays. Appl. Opt. 2017, 56, 5458-5462. [CrossRef] [PubMed]

38. Ye, Y.Q.; Jin, Y.; He, S. Omnidirectional, polarization-insensitive and broadband thin absorber in the terahertz regime. J. Opt. Soc. Am. B-Opt. Phys. 2010, 27, 498-504. [CrossRef]

39. Ma, M.S.; Wang, Y.; Navarro-Cia, M.; Liu, F.; Zhang, F.Q.; Li, Z.F.; Li, Y.X.; Hanham, S.M.; Hao, Z.C. The dielectric properties of some ceramic substrate materials at terahertz frequencies. J. Eur. Ceram. Soc. 2019, 39, 4424-4428. [CrossRef]

40. Du, X.; Yan, F.; Wang, W.; Tan, S.; Zhang, L.; Bai, Z.; Zhou, H.; Hou, Y. A polarization- and angle-insensitive broadband tunable metamaterial absorber using patterned graphene resonators in the terahertz band. Opt. Laser Technol. 2020, 132. [CrossRef]

41. Peng, X.L.; Hao, R.; Chen, W.C.; Chen, H.S.; Yin, W.Y.; Li, E.P. An Active Absorber Based on Nonvolatile Floating-Gate Graphene Structure. IEEE Trans. Nanotechnol. 2017, 16, 189-195. [CrossRef]

42. Shen, N.-H.; Tassin, P.; Koschny, T.; Soukoulis, C.M. Comparison of gold- and graphene-based resonant nanostructures for terahertz metamaterials and an ultrathin graphene-based modulator. Phys. Rev. B 2014, 90, 115437. [CrossRef]

43. Sorianello, V.; Midrio, M.; Romagnoli, M. Design optimization of single and double layer Graphene phase modulators in SOI. Opt. Express 2015, 23, 6478-6490. [CrossRef] [PubMed] 